\title{
MANAGEMENT OF SUGARCANE DISTILLERY SPENT WASH FOR IMPROVING THE GROWTH, YIELD AND QUALITY OF WHEAT CROP
}

\author{
Chattha, M. U. ${ }^{1}$ - HaKoomat, A. ${ }^{1}$ - Muhammad B. C..$^{2 *}$ Muhammad, U. C. ${ }^{3}-$ \\ MUHAMMAD, U. H. ${ }^{3,4}$ - MUHAMMAD N. ${ }^{5}$ \\ ${ }^{1}$ Department of Agronomy, Bahauddin Zakariya University, Multan, Pakistan \\ ${ }^{2}$ Institute of Agricultural Sciences, University of the Punjab, Lahore, Pakistan \\ ${ }^{3}$ Department of Agronomy, University of Agriculture, Faisalabad, Pakistan \\ ${ }^{4}$ Department of Agricultural and Food Sciences, University of Bologna, Bologna, Italy \\ ${ }^{5}$ College of Agriculture, Bahadur Campus Layyah, Bahauddin Zakariya University \\ Multan, Pakistan \\ *Corresponding author \\ e-mail: bilal1409@yahoo.com; phone:+92-300-766-5728
}

(Received $3^{\text {rd }}$ Aug 2017; accepted $3^{\text {rd }}$ Apr 2018)

\begin{abstract}
Disposal of industrial wastewater is a current issue of urbanization. However, this problem can be sorted out by using wastewater as an alternate source of irrigation after the addition of some amendment. The present study was performed at the Shakarganj Sugar Research Institute (SSRI) Jhang, Pakistan to determine the influence of different combinations of distillery spent wash (DSW) and NPK fertilizers on growth, yield and nutrient uptake of wheat crop. The experiment was composed of different combinations of DSW and NPK (0:0, 0:100, 25:75, 50:50, 75:25, 100:0). The results revealed that the application of different combinations of DSW and NPK significantly improved the growth, yield, and nutrient uptake in wheat crop. The maximum improvement in growth attributes (LAI, LAD, CGR and TDM) was recorded with the application of 25:75\% DSW and NPK fertilizers. Similarly, application of 25:75\% DSW and NPK improved the plant height, fertile tillers, 1000 grain weight, biological yield grain yield nitrogen uptake, phosphorus uptake and potassium uptake up to $32.88 \%, 37.5 \%, 38.87 \%, 34.61 \%$, $78.42 \%, 62.42 \%, 92.55 \%$ and $73.25 \%$ respectively, over the control. In conclusion, application of $25: 75 \%$ DSW and NPK was proven superior to other combinations in terms of growth, yield and nutrient uptake.

Keywords: wheat, spent wash, yield, grain, N. P. K.
\end{abstract}

\section{Introduction}

The imperious issue of water scarcity has devastating impacts on the economic growth, livelihoods and environmental supremacy around the globe. The rapid increase in industrialization excretes immense amount of waste water, as demands for fresh water is amplifying day by day, therefore, waste water often seen as a valuable asset, thus it can be a prime alternate source to irrigate the crops (Noori et al., 2013). Additionally, the agricultural crops also require a huge quantity of water for their growth and development. Therefore, the use of waste water in agriculture will solve both problems, and will improve the environmental quality and crop yield. Moreover, the use of waste water can improve the soil physical and chemical properties, soil nutrition status (Kiziloglu et al., 2007) and crop growth, yield as well as quality (Nagajyothi et al., 2009; Nath et al., 2009). Therefore, the wise use of waste water would be helpful in water conservation, nutrient recycling, reduction of water pollution and input application (Thapliyal et al., 2009; Vasudevan et al., 2010). 
The sugar industry plays a pivotal part in the economic development of Pakistan. There are 88 sugar mills in Pakistan (PSMA, 2014). These mills have limited capacity to store and to treat this spent wash, therefore, much of the spent wash is disposed into surrounding areas of mills. The poor handling and management of DSW create the problems of water pollution and deterioration of soil health (Chhonkar et al., 2000).

DSW is a by-product of sugar industry, it is purely of plant origin and contains appreciable amount of macro nutrients ( $\mathrm{N}, \mathrm{P}, \mathrm{K}, \mathrm{Mg}, \mathrm{Ca}$, and $\mathrm{S}$ ), micronutrients (Fe, $\mathrm{Zn}$ and $\mathrm{Mn}$ ) and organic matter, and therefore it can be a valuable fertilizer when applied to soil along with irrigation water (Vadivel et al., 2014). Likewise, DSW also contains a significant amount of growth promoting substances, i.e. auxins and gibberellins, which further increases its value as a fertilizer. The higher amount of calcium in DSW has the potential to reclaim the sodic soil, similarly to gypsum effect (Suganya and Rajannan, 2009).

The application of DSW not only controls the water pollution, but also improves the crop growth and productivity (Suganya and Rajannan, 2009). The application of DSW substantially improved the yield of sugarcane crop (Haron et al., 2004), rice and wheat yield (Pathak et al., 1998), and ground nut owing to improvements in soil quality and nutrient uptake (Ramana et al., 2001). Moreover, the use of DSW appreciably improved the crop productivity without affecting the soil fertility (Ramana et al., 2001).

The land application of DSW improved the microbial biomass, and enzymatic activities, which increased the mineralization of organic matter, thus improved the uptake and availability of nutrients (Mahimairaja et al., 2004). The judicious application of DSW enhanced the nutrient uptake in root vegetables (Chandraju et al., 2008), top vegetables (Basvaraju and Chandraju, 2008), leafy vegetables (Chandraju et al., 2007) and pulses (Chandraju et al., 2008).

The conjunctive application of synthetic fertilizers along with the organic fertilizers further improves the growth, yield and quality of crops. The combined application of DSW and NPK fertilizers, improved the growth, yield and nutrient uptake in sugar cane crop (Sharma, 2013). Likewise, the application of diluted DSW and NPK fertilizers improved the soil health, growth and yield and quality of sugarcane crop (Kaloi et al., 2017). On the basis of these facts, the present investigation was carried out to determine the suitable combination of spent wash and inorganic fertilizers, which has the best effect on growth, yield and nutrient uptake in wheat crop.

\section{Materials and methods}

\section{Study site and experimental design}

A Field study was conducted for two consecutive years $(2013-14,2014-15)$ at the farm of Shakarganj Mills Farms, Jhang, (longitude $73.8^{\circ} \mathrm{E}$, latitude $31.8^{\circ} \mathrm{N}$, and altitude $184.4 \mathrm{~m}$ asl) Pakistan to investigate the influence of different combination of distillery spent wash and NPK fertilizers on growth, yield and quality of wheat crop. The study site comes under sub-tropical region, moreover, the prevailing conditions during both growing seasons are given in Figure 1. Composite soil samples were taken from the site in order to determine the different physical and chemical properties of soil. The soil samples were analyzed by standard procedures of Homer and Pratt (1961). The soil was sandy loam, containing $0.74 \%$ organic matter, $0.058 \%$ nitrogen $(\mathrm{N}), 4.63 \mathrm{ppm}$ phosphorus $(\mathrm{P}), 121 \mathrm{ppm}$ potassium $(\mathrm{K})$, and has a $\mathrm{pH}$ of 7.94. The experiment was laid out in randomized complete block design having four replications. 


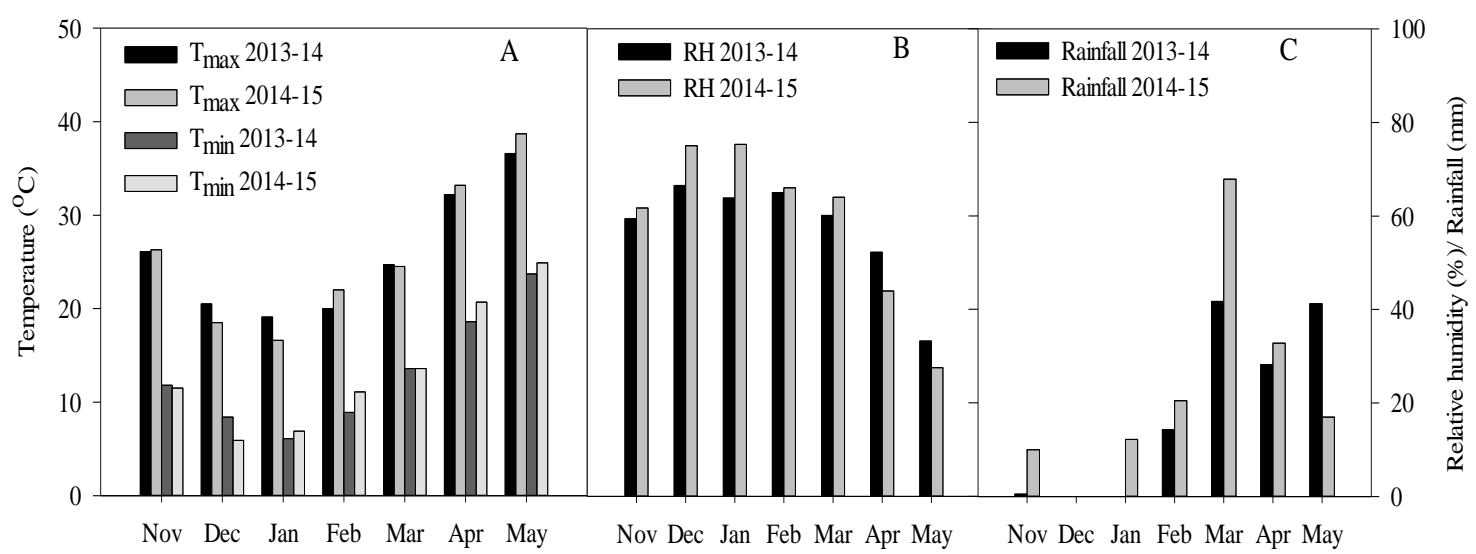

Figure 1. Prevailed climatic conditions during the growing seasons. A: Maximum and minimum temperature during 2013-14 and 2014-15, B: Relative humidity during 2013-14 and 2014-15,

C: Rainfall during 2013-14 and 2014-15

\section{Collection of spent wash and analysis}

Spent wash (SW) was collected from distillery of Shakarganj Mills. The spent wash samples were preserved in polycarbonyl sterilized air-free containers, after that they were transported into the laboratory and kept in refrigerator at $4{ }^{\circ} \mathrm{C}$ till use. The different components of spent wash like $\mathrm{pH}$, total solids, $\mathrm{N}, \mathrm{P}, \mathrm{K}, \mathrm{Ca}, \mathrm{Mg}, \mathrm{Na}, \mathrm{BOD}$ and COD (Table 1) were determined by the standard procedures of AWWA and WEF (1998).

Table 1. Characteristics of spent wash used in study

\begin{tabular}{c|c|c|c}
\hline $\mathrm{EC}\left(\mathrm{dS} \mathrm{m}^{-1}\right)$ & 7.7 & Total $\mathrm{Na}\left(\mathrm{mg} \mathrm{L}^{-1}\right)$ & 223 \\
$\mathrm{pH}$ & 4.1 & Total $\mathrm{P}\left(\mathrm{mg} \mathrm{L}^{-1}\right)$ & 75 \\
Organic matter (\%) & 1.25 & Total $\mathrm{N}\left(\mathrm{mg} \mathrm{L}^{-1}\right)$ & 410 \\
$\mathrm{BOD}\left(\mathrm{mg} \mathrm{L}^{-1}\right)$ & 232 & Total $\left(\mathrm{mg} \mathrm{L}^{-1}\right)$ & 2303 \\
$\mathrm{COD}\left(\mathrm{mg} \mathrm{L}^{-1}\right)$ & 6109 & $\mathrm{HCO}\left(\mathrm{mg} \mathrm{L}^{-1}\right)$ & 101 \\
Total Ca $\left(\mathrm{mg} \mathrm{L}^{-1}\right)$ & 124 & Indole acetic acid $\left(\mathrm{mg} \mathrm{L}^{-1}\right)$ & 41 \\
Total $\mathrm{Mg}\left(\mathrm{mg} \mathrm{L}^{-1}\right)$ & 63 & Gibberellic acid $\left(\mathrm{mg} \mathrm{L}^{-1}\right)$ & 3119 \\
\hline
\end{tabular}

\section{Treatment and crop husbandry}

The study was composed of the following treatments: $\mathrm{T}_{1}: 0 \% \mathrm{DSW}+0 \% \mathrm{NPK}, \mathrm{T}_{2}$ : $0 \% \mathrm{DSW}+100 \% \mathrm{NPK}, \quad \mathrm{T}_{3}: \quad 25 \% \mathrm{DSW}+75 \% \mathrm{NPK}, \quad \mathrm{T}_{4}: \quad 50 \% \mathrm{DSW}+50 \% \mathrm{NPK}, \mathrm{T}_{5}$ : $75 \% \mathrm{DSW}+25 \% \mathrm{NPK}$ and $\mathrm{T}_{6}: 100 \% \mathrm{DSW}+0 \% \mathrm{NPK}$. The seed bed was prepared as recommended by the department of agriculture, Punjab, Pakistan (Govt. of Punjab, 2013-14). The recommended rates of NPK for wheat crop were, 120:90:60 kg ha ${ }^{-1}$ and they were applied in the form of urea, diammonium phosphate and sulphate of potash. All the $\mathrm{P}$ and $\mathrm{K}$ fertilizers were applied at the time of sowing, while $\mathrm{N}$ was applied in two splits, i.e., at sowing and with first irrigation. The spent wash was applied with the first irrigation to the plots according to treatments. The distance between the sugarcane distillery and field was $1387 \mathrm{~m}$. The Punjab-2011 was used as test cultivars and sown in $23 \mathrm{~cm}$ apart lines by manual drill. During, both the growing seasons' five irrigations 
were applied to the wheat crop. All the management practices were kept uniform in order to get good production.

\section{Collection of growth and yield data}

Leaf area was measured by leaf area meter (Model: Licor 3000), whereas the leaf area index (LAI) was measured by the standard procedures of Watson (1947). Similarly, the leaf area duration (LAD) and crop growth rate (CRG) was measured by standard methods (Hunt, 1947). The unit area was selected to determine the number of fertile and un-fertile tillers, whereas, twenty plants were selected from each plot to determine the different yield and yield components (Chattha et al., 2017). At harvest grain and biological yield of each plot were measured and later on converted to ton per hectare basis mathematically (Chattha et al., 2017).

\section{Chemical analysis}

At harvesting, grain samples were collected from each plot, for analysis of grain NPK. The collected grain samples were dried in over at $72{ }^{\circ} \mathrm{C}$ until constant weight, after that they were grinded and sieved. The grinded samples were digested by adding di-acid mixture $\left(\mathrm{H}_{2} \mathrm{SO}_{4}\right.$ and $\mathrm{H}_{2} \mathrm{O}_{2}$ in $2: 1$ ratio). The grain $\mathrm{N}$ contents were determined by standard procedure of nitrogen Chapman and Parker (1961), whereas the P contents were measured by the Olsen et al. (1954) methods. Moreover, K was determined by flame photometer by using standard curve (Chapman and Parker, 1961).

\section{Statistical analysis}

In combined analysis the interaction of year (2013-14 and 2014-15) and treatments were found non-significant, therefore, the data was pooled for both years (2013-14 and 2014-15) and an average of two years was taken. The collected data regarding growth, yield and chemical analysis were analyzed by using analysis of variance technique and treatment means were compared by least significant difference test (Steel et al., 1997).

\section{Results}

\section{Influence of different combinations of spent wash and NPK fertilizers on growth} attributes of wheat crop

Different combinations of distillery spent wash (DSW) and NPK fertilizers significantly improved the growth attributes of wheat (Triticum aestivum L.) crop as compared to control (No DS and NPK) (Fig. 1). Crop attained maximum leaf area index (LAI) 75 days after sowing (DAS) with highest LAI value under the application of $25 \%$ DSW $+50 \%$ NPK fertilizers, that was comparable to the application of $50 \%$ DSW $+50 \%$ NPK, whereas the non-application of both DSW and NPK fertilizers remarkably decreased the LAI. Nonetheless a declining trend in LAI was recorded 75 DAS, whereas this declining trend was more pronounced when no DSW or NPK were applied followed by a $100 \%$ DSW application, whereas the minimum declining trend was found with the use of $25 \%$ DSW+75\% NPK (Fig. 3). Likewise, the effect of different combinations of DSW and NPK fertilizers was also significant on LAD, CGR and TDM. Crop attained maximum LAD and CGR 60-75 DAS, and this maximum LAD and CGR was recorded with the use of $25 \%$ DSW and $75 \%$ NPK, followed 
closely by the application of $50 \% \mathrm{DSW}+50 \% \mathrm{NPK}$ whereas the lowest LAD and CGR was recorded with no DSW and NPK application (Fig. 3). Similarly, TDM also increased with different combination of DSW and NPK, however, the highest TDM was recorded with the use of $25 \% \mathrm{DSW}+75 \% \mathrm{NPK}$, whereas no application of DSW and NPK fertilizers remarkably reduced the TDM (Fig. 3).

\section{Influence of different combinations of spent wash and NPK fertilizers on root growth and flag leaf length of wheat crop}

The influence of different combinations of DSW and NPK on root length and flag leaf length was substantiated (Table 2). The maximum root length $(13.10 \mathrm{~cm})$ and flag leaf length $(18.1 \mathrm{~cm})$ were recorded with application of $25 \%$ DSW and $75 \%$ NPK fertilizers, however, it was similar to application of $50 \%$ DSW and 50\% NPK, meanwhile the lowest root length $(7.5 \mathrm{~cm})$ and flag leaf length $(11.20 \mathrm{~cm})$ were recorded when no DSW or NPK were applied, nonetheless it was also comparable with application of $100 \%$ DSW.

Table 2. Effect of different combinations of DSW and NPK fertilizers on growth and attributes of wheat crop

\begin{tabular}{c|c|c|c|c}
\hline Treatments & $\begin{array}{c}\text { Root length } \\
(\mathbf{c m})\end{array}$ & $\begin{array}{c}\text { Flag leaf length } \\
(\mathbf{c m})\end{array}$ & $\begin{array}{c}\text { Plant height } \\
(\mathbf{c m})\end{array}$ & $\begin{array}{c}\text { No. of fertile tillers } \\
\left(\mathbf{m}^{2}\right)\end{array}$ \\
\hline Control & $7.50 \mathrm{c}$ & $11.20 \mathrm{~d}$ & $73.00 \mathrm{~d}$ & $226.67 \mathrm{c}$ \\
$0 \% \mathrm{DSW}+100 \% \mathrm{NPK}$ & $10.80 \mathrm{~b}$ & $16.51 \mathrm{c}$ & $87.66 \mathrm{bc}$ & $297.33 \mathrm{ab}$ \\
$25 \% \mathrm{DSW}+75 \% \mathrm{NPK}$ & $13.10 \mathrm{a}$ & $17.70 \mathrm{ab}$ & $95.00 \mathrm{a}$ & $305.67 \mathrm{a}$ \\
$50 \% \mathrm{DSW}+50 \% \mathrm{NPK}$ & $12.93 \mathrm{a}$ & $18.06 \mathrm{a}$ & $97.00 \mathrm{a}$ & $311.67 \mathrm{a}$ \\
$75 \% \mathrm{DSW}+25 \% \mathrm{NPK}$ & $11.36 \mathrm{~b}$ & $16.83 \mathrm{bc}$ & $91.66 \mathrm{ab}$ & $277.67 \mathrm{~b}$ \\
$100 \% \mathrm{DSW}+0 \% \mathrm{NPK}$ & $8.23 \mathrm{c}$ & $12.23 \mathrm{~d}$ & $82.33 \mathrm{c}$ & $246.33 \mathrm{c}$ \\
LSD $(p \leq 0.05)$ & $\mathbf{0 . 9 7}$ & $\mathbf{1 . 1 0}$ & $\mathbf{6 . 8 2}$ & $\mathbf{2 0 . 0 5}$ \\
\hline
\end{tabular}

Values sharing same letter(s) in a column do not differ at $5 \%$ probability

\section{Influence of different combinations of spent wash and NPK fertilizers on yield attributes of wheat crop}

Distillery spent wash and inorganic fertilizers significantly increased the yield attributes of wheat crop as compared to alone application of DSW, whereas the yield attributes considerably decreased when no DSW or NPK were applied (Tables 2 and 3). A significant increase in plant height was recorded with the use of DSW and NPK fertilizers compared to control. The application of $25 \% \mathrm{DSW}$ and $75 \% \mathrm{NPK}$ exhibited maximum improvement in plant height of wheat crop up to $32.88 \%$ over the control, nonetheless, it was comparable with $50 \% \mathrm{DSW}+50 \% \mathrm{NPK}$ and $100 \% \mathrm{DSW}$, whereas a substantial reduction in plant height was recorded under control treatment. Likewise, the effect of DSW and NPK on fertile and unfertile tillers was also significant. Maximum fertile tillers (311.67) was found with $25 \% \mathrm{DSW}$ and $70 \% \mathrm{NPK}$, followed by $50 \% \mathrm{DSW}+50 \% \mathrm{NPK}$, similarly, minimum fertile tillers were recorded in the control treatment. Additionally, minimum number of unfertile tiller (13.33) were counted from plot fed with $25 \%+75 \% \mathrm{NPK}$ that was the same with the application of 
$50 \% \mathrm{DSW}+50 \% \mathrm{NPK}$, moreover, the maximum unfertile tillers (26.67) were found in the control treatment. Regarding the 1000 grain weight combination of $50 \%$ DSW $+50 \%$ NPK increased the 1000 grain weight up to $26.24 \%$ that was the same with the application of $25 \% \mathrm{DSW}+75 \% \mathrm{NPK}$, whereas lowest 1000 grain weight was recorded with no DSW + NPK. Similarly, different levels of DSW and NPK fertilizers also had a significant effect on the biological yield and grain yield (Table 3). Similarly, up to $36.18 \%$ and $78.42 \%$ increase in biological and grain yield was found with the application of $25 \% \mathrm{DSW}+75 \% \mathrm{NPK}$, compared to control, however it was at par with the application of $50 \% \mathrm{DSW}+50 \% \mathrm{NPK}$.

Table 3. Effect of different combinations of DSW and NPK fertilizers on yield attributes of wheat crop

\begin{tabular}{c|c|c|c|c}
\hline Treatments & $\begin{array}{c}\text { No. of unfertile } \\
\text { tillers }\left(\mathbf{m}^{2}\right)\end{array}$ & $\begin{array}{c}\mathbf{1 0 0 0} \text { grain weight } \\
(\mathbf{g})\end{array}$ & $\begin{array}{c}\text { Biological yield } \\
\left(\mathbf{t ~ h a}^{-1}\right)\end{array}$ & $\begin{array}{c}\text { Grain yield } \\
\left(\mathbf{t ~ h a}^{-1}\right)\end{array}$ \\
\hline Control & $26.66 \mathrm{a}$ & $30.01 \mathrm{~d}$ & $7.60 \mathrm{~d}$ & $2.92 \mathrm{e}$ \\
$0 \% \mathrm{DSW}+100 \% \mathrm{NPK}$ & $18.66 \mathrm{c}$ & $35.33 \mathrm{c}$ & $9.11 \mathrm{c}$ & $4.44 \mathrm{c}$ \\
$25 \% \mathrm{DSW}+75 \% \mathrm{NPK}$ & $14.66 \mathrm{~d}$ & $41.66 \mathrm{a}$ & $10.23 \mathrm{ab}$ & $5.07 \mathrm{ab}$ \\
$50 \% \mathrm{DSW}+50 \% \mathrm{NPK}$ & $13.33 \mathrm{~d}$ & $40.66 \mathrm{ab}$ & $10.35 \mathrm{a}$ & $5.21 \mathrm{a}$ \\
$75 \% \mathrm{DSW}+25 \% \mathrm{NPK}$ & $19.33 \mathrm{c}$ & $37.00 \mathrm{bc}$ & $9.75 \mathrm{~b}$ & $4.74 \mathrm{bc}$ \\
$100 \% \mathrm{DSW}+0 \% \mathrm{NPK}$ & $22.33 \mathrm{~b}$ & $34.33 \mathrm{c}$ & $8.16 \mathrm{~d}$ & $3.53 \mathrm{~d}$ \\
LSD $(p \leq 0.05)$ & $\mathbf{1 . 7 8}$ & $\mathbf{4 . 1 6}$ & $\mathbf{0 . 5 8}$ & $\mathbf{0 . 3 3}$ \\
\hline
\end{tabular}

Values sharing same letter(s) in a column do not differ at $5 \%$ probability

\section{Influence of different combinations of spent wash and grain NPK uptake and grain NPK concentration}

The results revealed that the application of different combinations of DSW+NPK and alone DSW, NPK and control treatment had considerable effects on the nutrient uptake in wheat crop (Fig. 2). The maximum increase in nitrogen uptake was found with $25 \%+75 \%$ NPK application, i.e. $69.18 \%$ over the control, and similar trend was found with 50\%DSW+50NPK application. Moreover, minimum nitrogen uptake was found in the control treatment. A significant increase in phosphorus uptake was found with the use of $25 \% \mathrm{DSW}+75 \% \mathrm{NPK}$ treatment, i.e. $92.70 \%$ over the respective control (no DSW and no NPK application). Furthermore, K uptake also increased by application of DSW and NPK and maximum increase of $73.26 \%$ in $\mathrm{K}$ uptake was found by $25 \% \mathrm{DSW}+75 \% \mathrm{NPK}$, followed by $50 \% \mathrm{DSW}+50 \% \mathrm{NPK}$ that was similar to $100 \% \mathrm{DSW}$, meanwhile the minimum $\mathrm{K}$ uptake was found in control (No DSW+ No NPK). Similarly, different combinations of DSW+NPK fertilizers also had the considerable effect on the grain NPK concentration (Fig. 2). Maximum grain nitrogen concentration (2.8\%), phosphorus concentration $(0.49 \%)$ and potassium concentration $(1.05 \%)$ was recorded with application of $25 \% \mathrm{DSW}+75 \% \mathrm{NPK}$, however, it was comparable with $50 \% \mathrm{DSW}+50 \% \mathrm{NPK}$, whereas the minimum grain nitrogen $(1.10 \%)$ phosphorus $(0.24 \%)$ potassium $(0.40 \%)$ was observed in the control treatment. 

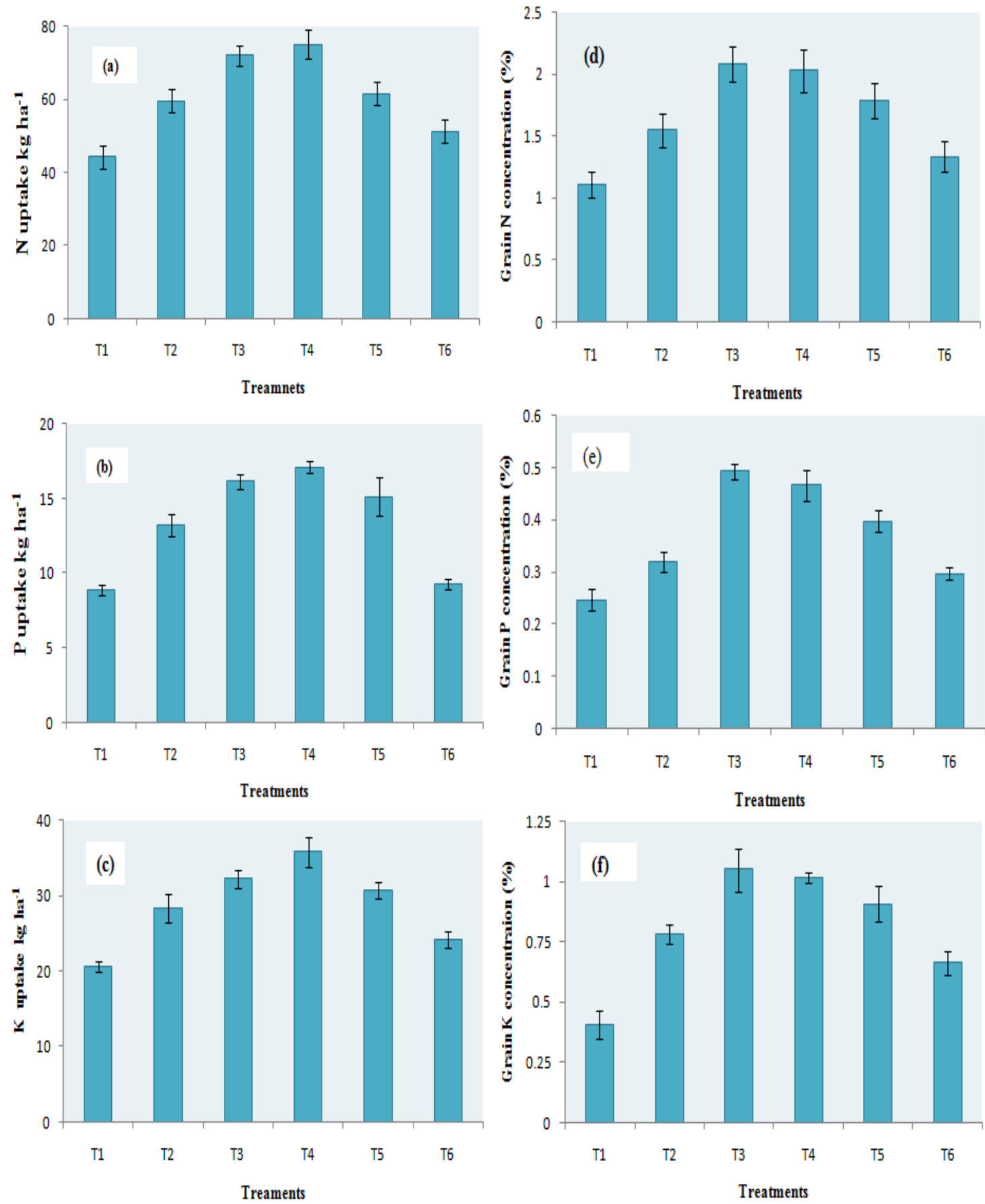

Figure 2. Influence of different combinations of $D S W+N P K$ fertilizers on grain NPK uptake $(a, b, c)$ and grain NPK concentration $(e, f, g)$

\section{Discussion}

The rapid growth of the population substantially increased the quantity of industries around the globe. These industries excrete a huge amount of waste water, which is continuously deteriorating our environment. As the fresh water resources are declining and the demand of fresh water is increasing day by day due to blooming population, waste water usage in agriculture for irrigation purposes may offer a solution to this 
problem. Moreover, this waste also contains undesirable substances which can deteriorate the soil health, crop yield and environmental quality. However, the use of this water along with certain amendments can reduce its negative impacts on soil health, crop, environment and microbial activities. The application of NPK fertilizers along with DSW is a viable strategy to reduce the negative impacts of DSW on soil and crop. The present study determines the effectiveness of different combinations of DSW along with NPK fertilizers on the growth, yield, and nutrient uptake in wheat (Triticum aestivum L.) crop. The results revealed that the application of different combinations of DSW+NPK significantly improved the growth attributes, i.e. LAI, LAD, CGR, TDM, as compared to alone application of DSW and no application of DSW and NPK (Fig. 3).
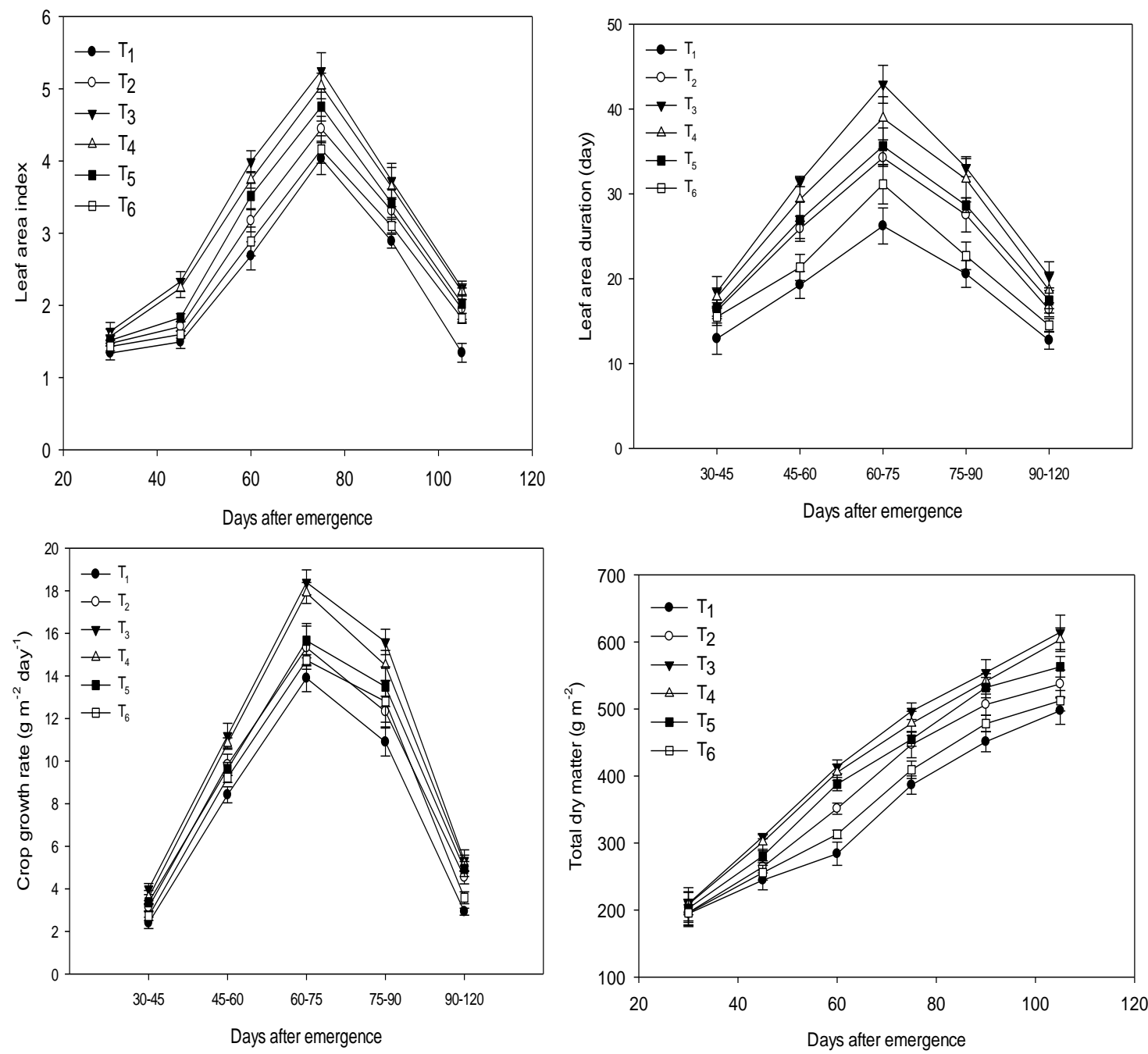

Figure 3. Influence of different combinations of DSW and NPK fertilizers on LAI, LAD, CGR and TDM

The increase in growth attributes of wheat crop (LAI, LAD) at lower concentration of DSW might be due to improved root length, which resulted in better absorption of nutrient and water thereby improved the growth attributes. Likewise, the maximum CGR and TDM were found with application of $25 \% \mathrm{DSW}+75 \% \mathrm{NPK}$. This improvement in CGR and TDM can be due to increased flag leaf length; therefore, the plants having longer flag leaf absorbed more 
light, that resulted in production of more assimilates; thus produced more CGR and TDM. Similarly, Ramana et al. (2001) and Nandy et al. (2002) reported that application of DSW at lower concentrations significantly improved the growth attributes of rice and maize crop due to better availability of nutrients. Similarly, the reduction in growth attributes of wheat crop at higher concentration of DSW might be due to the presences of higher quantity of organic matter and BOD, which resulted in depletion of soil oxygen and accumulation of carbon dioxide in soil (Rath et al., 2010).

Likewise, the DSW+NPK also improved the root length, flag leaf length and plant height of wheat crop. The improvement in root length, flag leaf length, by application of the lower concentration of DSW, can be due to the presence of decreased amount of salts. Therefore, the application of DSW has substantially improved microbial activities which improved the decomposition of organic matter thus improved the nutrient uptake and therefore the plant growth. These results are supported by previous findings of Rajkishore and Vignesh (2012), who found that application of DSW at lower concentration substantially improved the microbial activities, therefore, increased the nutrient uptake and availability and thereby improved plant growth. Similarly, the various combinations of DSW and inorganic fertilizers had considerable effects on the yield and yield attributes of wheat crop (Table 3). The improvement in yield attributes of wheat crop by lower doses of DSW might be due to the improvement of soil properties, which resulted in better availability of nutrient and thereby improved the growth attributes. Moreover, the lower dose of DSW and application of higher dose of NPK might have increased the concentration of nutrients in soil solutions that overcome the toxic effects of heavy metals. Conversely, higher concentration of DSW might have increased the salt accumulation in the root which resulted in higher osmotic pressure within the root zone. This increase in osmotic pressure can substantially reduce the nutrient uptake, thereby, reduced the crop yield and yield components. These results are in line with previous findings of earlier researchers who reported that application of DSW at lower concentration remarkably improved the growth, yield and yield attributes (Mahimairaja and Bolan, 2004; Chandraju et al., 2008; Chidankumar et al., 2009). Similarly, Rath et al. (2010) reported that application of higher concentration of DSW significantly decreased the growth, and yield of sugarcane crop.

The results showed that conjunctive application of DSW+NPK fertilizers considerably improved the nutrient uptake in wheat crop (Fig. 2). The increase in nutrient uptake by DSW+NPK might be due to the presence of appreciable amounts of nutrients in DSW and improvement in soil conditions due to DSW application. Similar results were reported by many researchers who reported that application of DSW improved the uptake of nutrients (Chandraju et al., 2008; Chidankumar et al., 2008; Basvaraju and Chandraju, 2008). Moreover, the application of DSW remarkably improved grain NPK concentration. The improvement in grain NPK concentration by lower DSW might be due to the counter effect of beneficial nutrients, reduction in metal toxicity, and improvement of microbial activity that produces chelate and hormones, which improved growth, yield and nutrient uptake in wheat crop.

\section{Conclusion}

Distillery spent wash contains many important nutrients; therefore, it can be used to grow the crops along with inorganic fertilizers. This study implies that combination of $25 \% \mathrm{DSW}+75 \% \mathrm{NPK}$ could be a viable strategy, and it can remarkably improve the growth, yield, and quality of wheat crop. 


\section{REFERENCES}

[1] APHA, AWWA, WEF (1998): Standard Methods for Examination of Water and Wastewater (20th ed.). - American Public Health Association, Washington, DC.

[2] Basavaraju, H. C., Chandraju, S. (2008): Impact of distillery spentwash on the nutrients of leaves vegetables: An investigation. - Asian J Chem 20(7): 5301-5310.

[3] Chandraju, S., Basavaraju, H. C. (2007): Impact of distillery spentwash on seed germination and growth of leaves vegetables: An investigation. - Sugar J (SISSTA) 38: 20-50.

[4] Chandraju, S., Basavaraju, H. C., Chidankumar, C. S. (2008): Investigation of impact of irrigation of distillery spentwash on the growth, yield and nutrients of leafy vegetable. Chem Env Res 17: 84-92.

[5] Chidankumar, C. S., Chandraju, S., Girijanagendraswamy, N. R. (2008): Nutritional additives of spentwash on pulses production. - J Bio Pestic 3: 51-54.

[6] Chidankumar, C. S., Chandraju, S., Nagendraswamy, N. (2009): Impact of distillery spent wash irrigation on the yields of top vegetables (creepers). - World Appl Sci J 6(9): 12701273.

[7] Chattha, M. U., Muhammad, U. H., Imran, K., Muhammad, B. C., Athar, M., Muhammad, U. C., Muhammad, N., Muhammad, N. S., Mina, K., Sadia, K. (2017): Biofortification of wheat cultivars to combat zinc deficiency. - Front. Plant Sci. 8(281): $1-8$.

[8] Chapman, H. D., Parker, F. (1961): Determination of NPK. Method of analysis for soil, plant and water, pp. 150-179. - Div. Agric, Univ. California, USA.

[9] Chhonkar, P. K., Datta, S. P., Joshi, H. C., Pathak, H. (2000): Impact of industrial effluents on soil health and agriculture Indian experience: part I, distillery and paper mill effluents. - J Sci Indus Res 59: 350-336.

[10] Govt. of Punjab (2013-14): Production Plan of Wheat. - Department of Agriculture Government of Punjab, Lahore.

[11] Haron, M. A. R., Subash, M., Bose, C. (2004): Use of distillery spentwash for alkali soil reclamation, treated distillery effluent for ferti irrigation of crops. - Indian Farming 3: 4851.

[12] Homer, D. C., Pratt, P. F. (1961): Methods of Analysis for Soils, Plants and Waters. University of California, Davis.

[13] Hunt, R. (1978): Plant growth analysis. The institute Biology's studies in Biology. Edward Arnold (Pub.) Ltd., London.

[14] Kaloi, G. M., Mehrunis, M., Kazi, S. M., Sagheer, A., Saghi, A. H., Ghulam, M. J. (2017): Effect of sugar industry spentwash (diluted) on the characteristics of soil and sugarcane (Saccharum officinarum L.) growth in the subtropical environment of Sindh, Pakistan. - Environ Monit Assess 12: 1-13.

[15] Kiziloglu, F. M., Turan, M., Sahin, U., Angin, I., Anapali, O., Okuroglu, M. (2007): Effects of waste water irrigation on soil and cabbage-plant (Brassica olerecea var. capitate cv. Yalova-1) chemical propert ies. - J Plant Nutr Soil Sci 170: 166-172.

[16] Mahimairaja, S., Bolan, B. N. (2004): Problems and prospects of agricultural use of distillery spentwash in India. - Third Australian and New Zealand Soil Science Societies Joint Conference, Sydney, Australia.

[17] Nagajyothi, P. C., Dinakr, N., Suresh, S., Udaykiran, Y., Suresh, C., Damodharam, T. (2009): Effect of industrial effluent on the morphological parameters and chlorophyll content of green gram (Phaseolus aureus Roxb). - J Environ Biol 30: 385-388.

[18] Nath, K., Singh D, Shyam, S, Sharma, Y. K. (2009): Phytotoxic effects of chromium and tannery effluent on growth and metabolism of Phaseolus mungo Roxb. - J Environ Biol 30: 227-234.

[19] Nandy, T., Shastri, S., Kaul, S. N. (2002): Wastewater management in a care distillery involving bioresource recovery. - J. Environ. Manag. 65: 25-38. 
[20] Noori, M., Mahdiye, M., and Norozi, R. (2013): Waste water irrigation effects on growth parameters of Alyssum longistilum Grossh. (Brassicaceae) a medicinal plant in Iran. The International Conference on Women in Science and Technology in the Arab Countries, 21-23 April 2013, Kuwait.

[21] Olsen, R., Cole, C. V., Watanabe, F. S., Dean, L. A. (1954): Estimation of available phosphorus in soils by extraction with sodium bicarbonate. - Circular 939. United States Department of Agriculture, Washington (DC).

[22] Pathak, H., Josh., H. C., Chaudhary, A., Karla, N., Dwivedi, M. K. (1998): Distillery effluent as soil amendment for wheat and rice. - J Indian Soil Sci 46: 155-157.

[23] PSMA (2014): Annual Report, pp. 21-23. - Pakistan Sugar Mills Association, Lahore, Pakistan.

[24] Ramana, S., Biswas, A. K., Kundu, S., Saha, J. K., Yadava, B. R. (2001): Effect of distillery effluent on seed germination in some vegetable crops. - Bioresour Technol 82: 273-275.

[25] Rajkishore, S. K., Vignesh, N. S. (2012): Distillery spentwash in the context of crop production: a review. - Inter Quart J Life Sci 7(3): 369-375.

[26] Rath, P., Pradhan, G., Mishra, M. K. (2010): Effect of sugar factory distillery spent wash (dsw) on the growth pattern of sugarcane (saccharum officinarum) crop. - J Phyto Plant Physio 2(5): 33-39.

[27] Sharma, A. (2013): Effect of spent wash and chemical fertilizer on yield, nutrient uptake and quality of sugarcane. - Technofame 2(2): 35-38.

[28] Suganya, K., Rajannan, G. (2009): Effect of one time post-sown and pre-sown application of distillery spentwash on the growth and yield of maize crop. - Bot Res Intern 2(4): 288-294.

[29] Steel, R. G. D., Torrie, J. H., Dickey, D. A. (1996): Principles and procedures of statistics: a biometric approach. Third ed. - McGraw Hill Book Co. Inc., New York, USA.

[30] Thapliyal, A., Vasudevan, P., Dastidar, M. G. (2009): Domestic waste water for fertigation: A solution for water recycling and irrigation. Proceedings of Micropol and Ecohazard. - 6 I WA/ GRA Specialized Conference on Assessment and Control of Micropollutants Hazardous Substances in Water. 8-10 June 2009, San Francisco, California, USA.

[31] Vadivel, R. V., Paramjit, S. M., Suresh, K., Yogeswar, S. N., Rao, D. V. K., Avinash, N. (2014): Significance of vinasses waste management in agriculture and environmental quality. Review. - Afric J Agricul Res 9(38): 2862-2873.

[32] Vasudevan, P., Thapliyal, A., Srivastava, R. K., Pandey, A., Dastidar, M. G., Davies, P. (2010): Fertigation potential of domestic waste water for tree plantations. - J Scientific Indus Res 69: 146-150.

[33] Watson, D. J. (1947): Comparative physiological studies in the growth of field crops. I: Variation in net assimilation rate and leaf area between species and varieties, and within and between years. - Ann Bot 11: 41-76. 